\title{
Numerical simulation of heat transfer during leaf spring industrial quenching process
}

\author{
Salma Slama ${ }^{1, *}$, Mahmoud Bouhafs ${ }^{1}$, Jamel Bessrour ${ }^{1}$, Moez Ben Jaber ${ }^{2}$, and Hassan Mokdadi ${ }^{3}$ \\ ${ }^{1}$ Laboratory of Applied Mechanics and Engineering, University of Tunis EL Manar, National Engineering School of Tunis, \\ BP 37, Le Belvédère, 1002, Tunisia \\ ${ }^{2}$ Laboratory of Systems and Applied Mechanics, University of Carthage, Polytechnic school, La Marsa, Tunisia \\ ${ }^{3}$ Cavéo Automotive Compagny BP 912, ZI Borj Cedria 2050, Tunisia
}

Received: 18 July 2016 / Accepted: 13 February 2018

\begin{abstract}
This study is carried out in partnership with the company CAVEO, manufacturer of leaf springs for vehicles. It concerns the development of a numerical model intended to follow the space-time temperature evolution of a leaf during two processing operations: hot cambering and quenching. This leaf is of a parabolic profile, made of EN-51CrV4 steel (AISI-6150). After austenitization, it passes through a cambering operation to confer it the desired deflection and then a quenching operation. This quenching is carried out in an oil bath to achieve better mechanical properties. The prediction of the temperature during quenching involves determining the heat transfer coefficient between the leaf and the oil bath. This coefficient is determined by quenching, under the same conditions as the leaf, using a standard probe of the same steel. The numerical model is based on the resolution of the transient heat equation by considering the heat loss flows towards the heterogeneous environment (ambient air, press contact and quenching oil). The results obtained by this model give the spacetime temperature evolution of the leaf from the exit of the heating furnace to the exit of the oil bath. The numerical results are compared to the experimental profiles obtained through thermographic images throughout cambering and quenching operations. These results are consistent with experimental results.
\end{abstract}

Keywords: Numerical model / leaf spring / quenching / heat transfer coefficient / temperature evolution

\section{Introduction}

The leaf springs for rolling vehicles, manufactured by the company CAVEO, pass during their industrial manufacturing by several successive operations. This study concerns two of these operations, hot cambering and quenching. These two operations are combined; the first concerns, after complete austenitization of the leaf, the hot cambering on a press to give the desired deflection. It is followed by the quenching operation in an oil bath to achieve a martensitic structure on both surface and core.

The parameters governing these two operations are currently determined through the manufacture of several leaf prototypes tested at the production line. In order to avoid the extra cost, these prototypes will be replaced by virtual prototypes based on numerical simulation.

The objective of this work is therefore to develop a reliable numerical model capable of predicting the spacetime temperature evolution for any geometry of leaf from the exit of the heating furnace until the exit of the oil bath.

\footnotetext{
* e-mail: salma.slama1@yahoo.com
}

Thus, it will optimize the different parameters of these two operations and facilitate the development of new ranges of springs.

Several studies are published on the numerical simulation of various industrial processes of hot forming and quenching of mechanical components [1] such as automotive ones [2]. Most of this work concerns the hot stamping of thin components where forming and quenching operations are combined in one step [3]. The most common steels used in these studies are high strength steels such as boron steels [4]. Our model relates to a particular manufacturing process that has parameters that differ from the published studies in terms of geometry, material, forming and quenching conditions.

In this paper, the proposed model is developed under the Abaqus finite element code in its implicit version. It is intended to solve the transient heat equation by taking into account the thermal losses caused during these operations. The modeling of the quenching operation involves determining the heat transfer coefficient between the leaf and the oil bath. This coefficient was determined experimentally and in accordance with the leaf quenching conditions. 


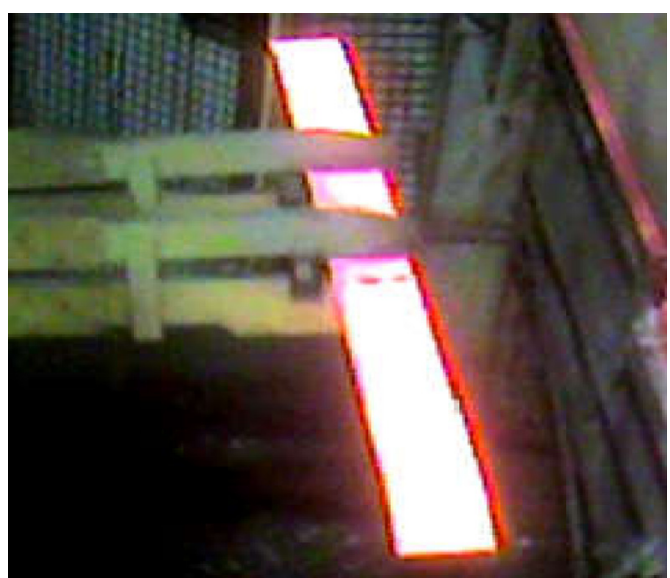

1a: Leaf exit from the furnace

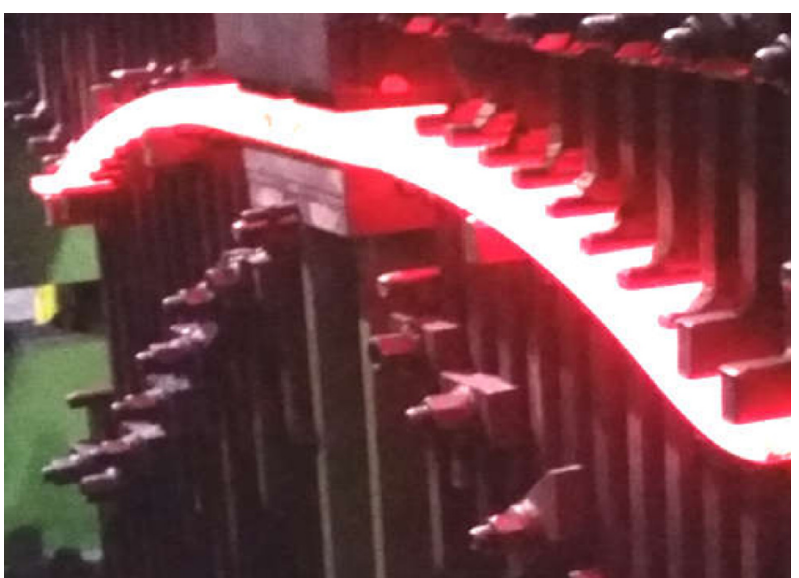

$1 b$ : Leaf cambering operation

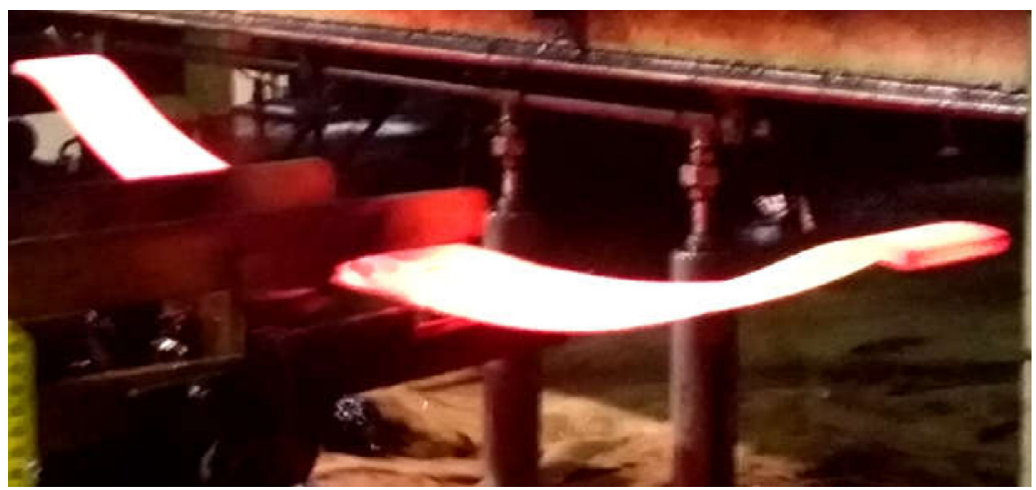

1c: Leaf at the moment of quenching in an oil bath

Fig. 1. Leaf spring manufacturing process: austenitization, cambering and quenching.

The results obtained by the numerical simulation are then compared with experimental measurements carried out by infrared thermography camera. The comparison concerns the distribution of the temperature throughout the cambering and the quenching.

\section{Study overview}

This study deals specifically with the leaf cambering and quenching operations. The mechanical properties of the leaf after quenching are conditioned by the parameters which govern these operations. These parameters include the austenitization temperature, the cambering duration, the temperature of the quench oil, the cooling rate and duration

The aim of this research is to control those parameters in order to avoid leaf defects (cracks, surface decarburization, internal stresses, fragility...), to facilitate and optimize the development of new spring ranges.

\subsection{Leaf spring processing}

The two integrated cambering and quenching operations follow a programmed cycle specific to each range of leaf. This cycle, starts by the leaf heating whose purpose is to reach a homogeneous austenitic structure (Fig. 1a). At the exit of the leaf from the furnace, the leaf is transferred by robot on a press so as to undergo the cambering and to confer it the deflection corresponding to its profile (Fig. 1b). Finally, the leaf is transported by a second robot and quenched in an oil bath at a temperature varying between 60 and $80^{\circ} \mathrm{C}$ (Fig. 1c).

The transfer of the leaf from the furnace to the quenching bath induces a thermal loss in relation to the selected austenitising temperature, the mass, the thickness of the leaf and the temperature of the surrounding medium. This loss of temperature must not reach the temperature of transformation of the austenite into bainite at the moment of their immersion in the oil. The holding time in the oil bath must allow the cooling of the leaf to reach the temperature of the bath.

\subsection{Geometry and material of the leaf}

The leaf selected for this study is symmetric and have a parabolic profile (Fig. 2). Typical dimensions of the leaf: $1.5 \mathrm{~m}$ long, $100-\mathrm{mm}$ wide and thickness varying from $40 \mathrm{~mm}$ at the level of the leaf central axis (zone 1) to $14 \mathrm{~mm}$ at the extremities. Within zone 2 , the profile is parabolic and the thickness varies between the extreme values. 




Fig. 2. Geometry of a parabolic leaf.

Table 1. Chemical composition of the steel $51 \mathrm{CrV} 4$ [5].

\begin{tabular}{lccccccc}
\hline Elements & $\% \mathrm{C}$ & $\% \mathrm{Mn}$ & $\% \mathrm{Si}$ & $\% \mathrm{P} \max$ & $\% \mathrm{~S} \max$ & $\% \mathrm{Cr}$ & $\% \mathrm{~V}$ \\
\hline $51 \mathrm{CrV} 4$ & $0.47-0.55$ & $0.70-1.10$ & $\max .0 .40$ & 0.025 & 0.025 & $0.9-1.2$ & $0.10-0.25$ \\
\hline
\end{tabular}

This leaf is manufactured by CAVEO in normalized steel EN-51CrV4 (AISI-6150). Its chemical composition is provided in Table 1 and follows standard EN-10089.

\section{Experimental investigation}

The development of the numerical model for this study will require:

- the experimental measurements of the leaf temperature throughout the cambering and quenching operations on the production line;

- to determine the heat transfer coefficient between the leaf and the quenching oil under the processing conditions.

\subsection{Temperature measurement}

A calibrated infrared camera (FLIR ThermaCAM P60) is used to measure the leaf temperature throughout exit from the heating furnace to exit from the quenching bath.

- At the moment of its exit from the furnace at time $\left(t_{0}=0 \mathrm{~s}\right)$, the temperature measurements delivered by the camera are between 930 and $900{ }^{\circ} \mathrm{C}$ in zone 2 and between 900 and $850^{\circ} \mathrm{C}$ in zone 1 (Fig. 3). The temperature hooks at $418^{\circ} \mathrm{C}$ correspond to the temperature of the robot clamps.

- At the time $\left(t_{1}=34 \mathrm{~s}\right)$, at the moment of immersion of the leaf in the oil bath, the temperatures displayed by the camera are in Figure 4. They are presented by three curves corresponding respectively to $\mathrm{Li} 1, \mathrm{Li} 2$ and $\mathrm{Li} 3$ (Fig. 4b) to take into account the curvature of the leaf.

- Li1 and Li3 are segments respectively, representing the zone 2 of the leaf. The temperature on these segments varies between 850 and $800^{\circ} \mathrm{C}$;

- Li2 is a segment corresponding to zone 1 . The temperature in this segment varies between 860 and $730^{\circ} \mathrm{C}$. The temperature hook which is present on this curve is associated with the thermal loss caused by the contact of the leaf with the jaws of the press and the clamps of the transfer robot.

- At time $\left(t_{2}=34+440 \mathrm{~s}\right)$, the leaf temperatures at the exit from the oil bath are shown in Figure 5. They are also of three curves, respectively, corresponding to Li1, Li2 and Li3 (Fig. 5b).

- Li1 and Li3 are segments of the leaf showing the zone 2. The temperature of these segments range from 75 to about $147^{\circ} \mathrm{C}$;

- Li2 is the central segment of the leaf corresponds to zone 1. The temperature in this segment varies between 126 and $153^{\circ} \mathrm{C}$.

These experimental results of temperature measurements taken by the infrared camera will be used for comparison with the numerical calculations.

\subsection{Temperature-dependent transfer coefficient}

The development of the numerical model relies notably on the determination of the transfer coefficient $h_{\text {oil }}(T)$ between the leaf and the quenching bath. This coefficient varies considerably with the temperature [6], the quenching environment characteristics [7] (agitation [8], viscosity,...), and the quenched material (enthalpy changes) [9].

The transfer coefficient $h_{\mathrm{oil}}(T)$ is calculated from the following analytic expression (Eq. (1)) [10]:

$$
\frac{h(T)=V \cdot \rho(T) \cdot C(T) \cdot \dot{T}}{A\left(T_{S}-T_{b}\right)}
$$

with

$\rho(T)$ :density, $V$ : probe volume, $\mathrm{C}(T)$ : specific heat, $(\dot{T})$ : cooling rate, $A$ : probe surface,

$T_{S}$ : temperature of the probe surface, $T_{b}$ : temperature of the quenching bath.

The experimental determination of the leaf cooling rate $(\dot{T})$ during quenching is difficult to achieve, since the oil bath is not accessible. Alternatively, a standardized probe (standard AFNOR NFT 60-178) was used in place of the leaf. It is a cylindrical probe [11] of a 16-mm diameter and a 48-mm height. The probe is usually made from metal without any phase transformation such as inconel [12], silver [13] and austenitic steel.

In this study, the probe is made from the same steel as the leaf $(51 \mathrm{CrV} 4)$ to take into account the enthalpy changes due to phase transformation during this probe 
3.a: Infrared image

3.b: Temperature profile along the leaf
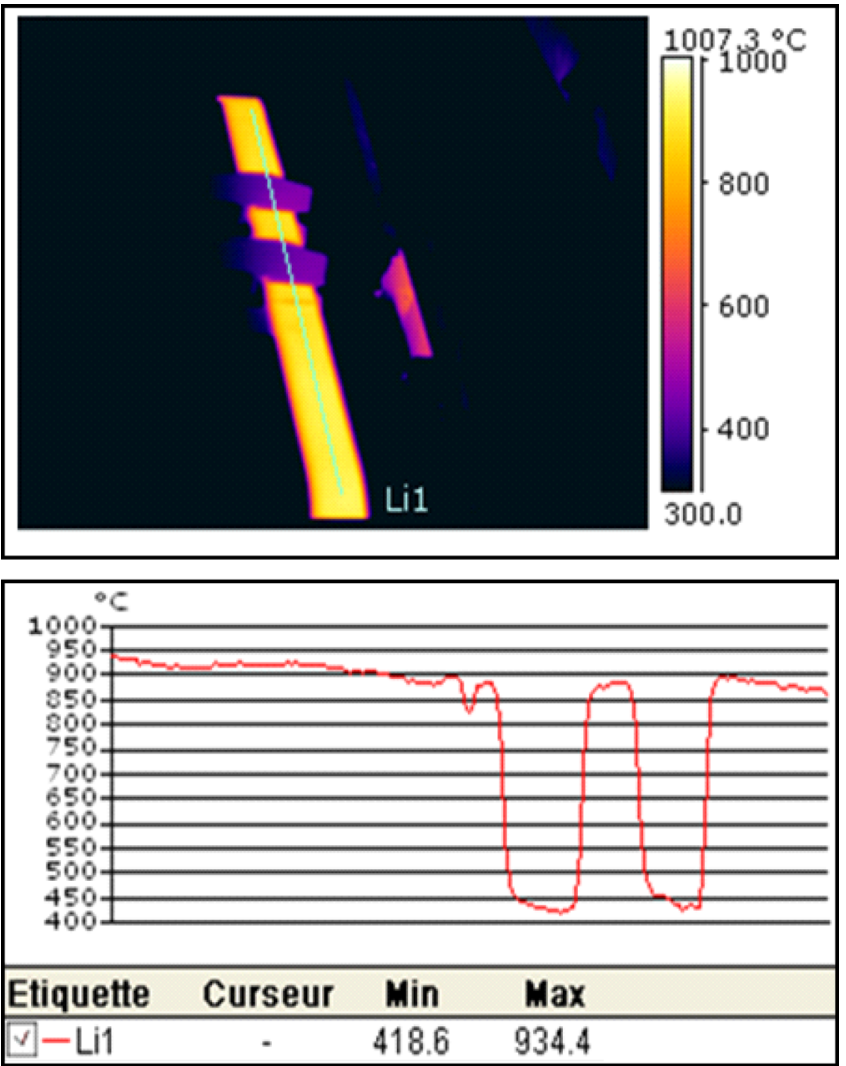

Fig. 3. Leaf temperature at $t_{0}$.
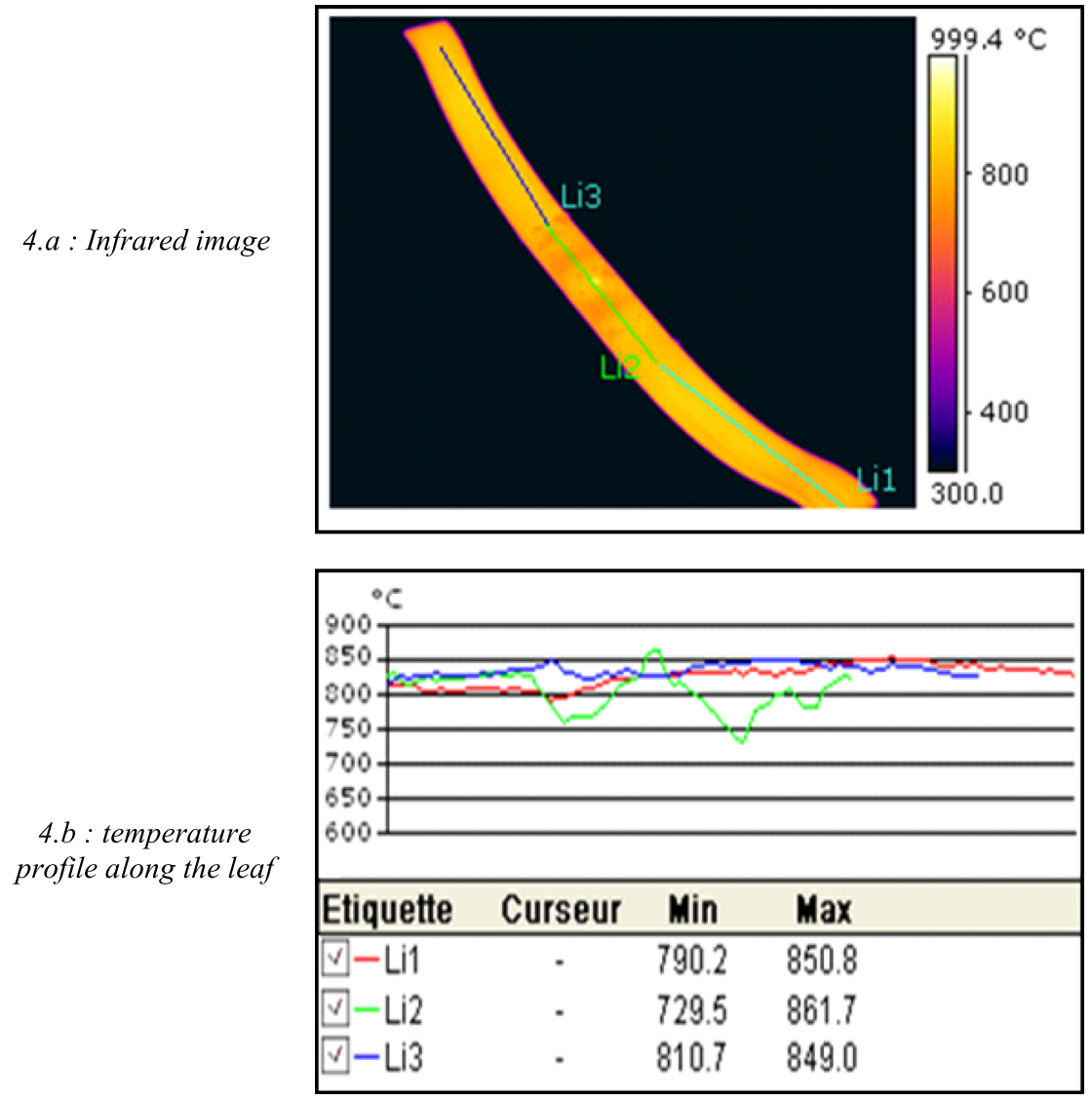

Fig. 4. Leaf temperature at $t_{1}$. 


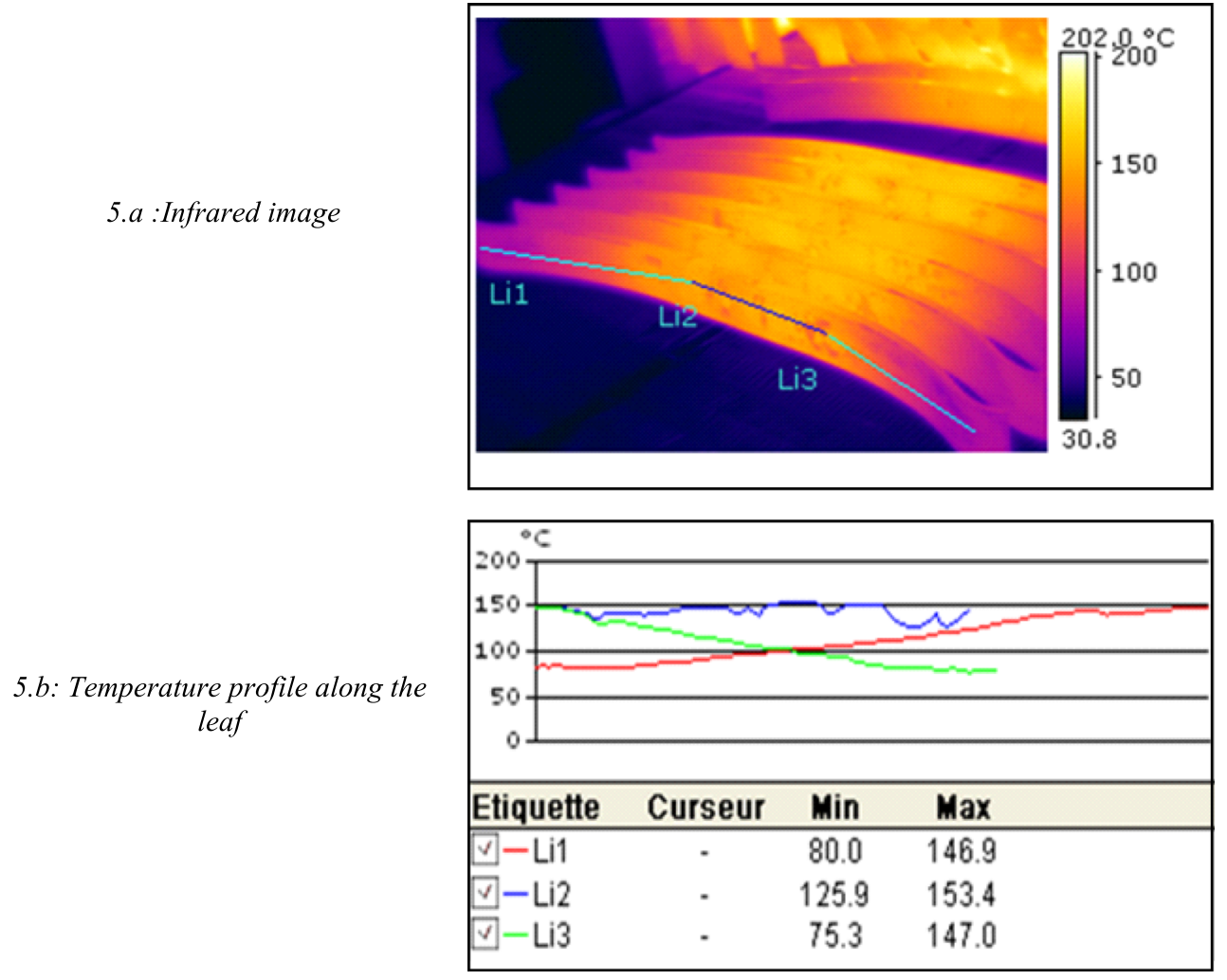

Fig. 5. Leaf temperature at $t_{2}$.

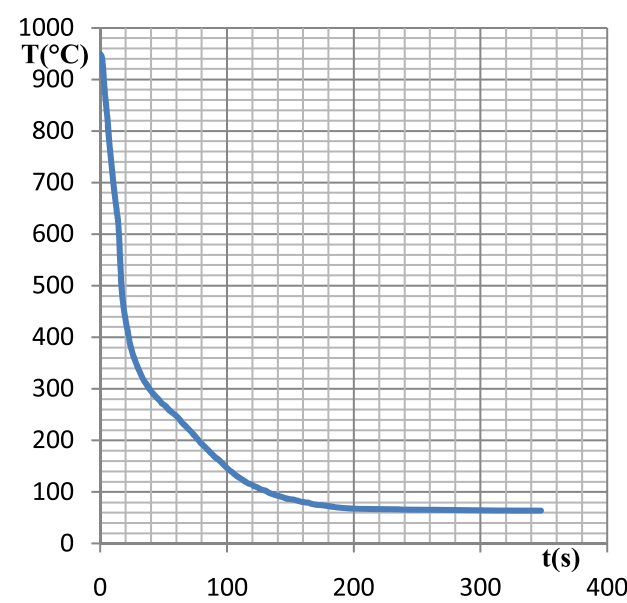

Fig. 6. Measured cooling curve of the probe $T=f(t)$.

quenching. This probe is drilled in its axis of a hole $4 \mathrm{~mm}$ in diameter and $24 \mathrm{~mm}$ depth. This hole is used to accommodate the K-type thermocouple connected to an acquisition chain with 1000 measurements per second. This probe is then austenitized with its thermocouple at $950^{\circ} \mathrm{C}$ and then quenched in oil under the same conditions as the leaf. The temperatures during heating and cooling of this probe are recorded by means of this chain. In order to avoid erroneous readings and to ensure the repeatability of the experiment, three quenching tests were carried out using calibrated thermocouple with following dispositions; thermocouple protection, shielded compensation wires, copper grease (for better thermal contact). Finally, the control of signals acquisition and their archiving is carried out by an acquisition software (QuiqDaq v1.6). The results provided by QuiqDaq were filtered by a digital low pass filter in order to reduce the noise of time-temperature data.

The layout of the temperature variation measured according to time (Fig. 6) during this probe quenching shows the inflexions highlighted on the derivative of the cooling curve (temperature according to the cooling rate $\left.\left(\dot{T}=\frac{d T}{\mathrm{~d} t}\right)\right)$ (Fig. 7). It reveals clearly the three cooling modes [14] that are separated by the characteristic oil temperatures $\theta_{1}=630^{\circ} \mathrm{C}$ and $\theta_{2}=400^{\circ} \mathrm{C}$, namely:

- the vapor phase or stage between 950 and $630^{\circ} \mathrm{C}$ with $\dot{T}$ varying between 20 and $30^{\circ} \mathrm{Cs}^{-1}$;

- the boiling phase between 630 and $400{ }^{\circ} \mathrm{C}$ with $\dot{T}_{\max }$ around $50^{\circ} \mathrm{C} \mathrm{s}^{-1}$;

- the convection phase between 400 and $70{ }^{\circ} \mathrm{C}$, with a weak cooling rate.

The calculation of $h_{\mathrm{oil}}(T)$ through equation 1 allows us drawing the coefficient variation curve according to the temperature (Fig. 8). The curve profile follows the same course as Figure 7 and highlights three different cooling modes, with $h_{\text {oil }}$ values around $750 \mathrm{Wm}^{-2}{ }^{\circ} \mathrm{C}^{-1}$ for the first mode, reaching the peak of $2020 \mathrm{Wm}^{-2}{ }^{\circ} \mathrm{C}^{-1}$ for the second and falls during the third. These three phases are actually those of the vapor, boiling and convection phase, separated by nearly the same temperature values $\theta_{1}$ and $\theta_{2}$. This layout turns out to be in accordance with the other works that concerned the determination and the validation of the transfer coefficient of the quenching oils $[15,16]$. 


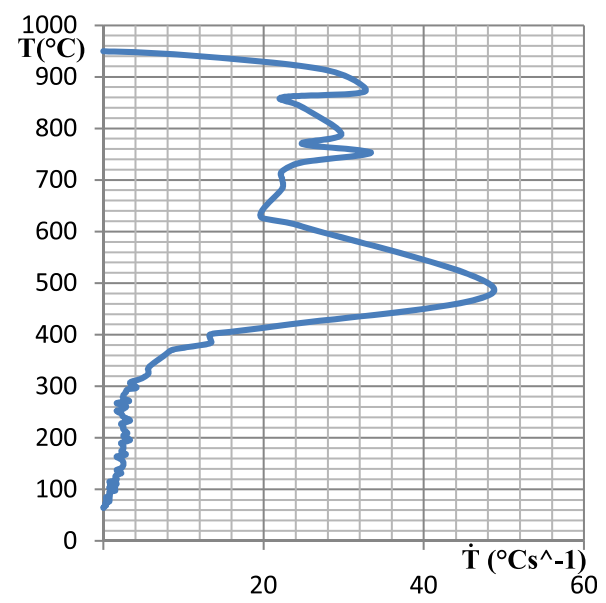

Fig. 7. Derived curve $T=f(\dot{T})$.

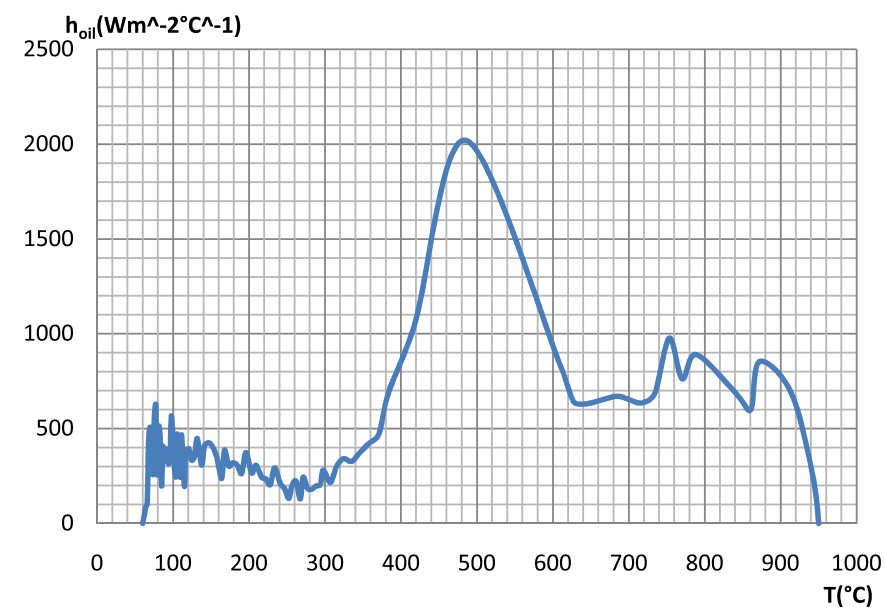

Fig. 8. Evolution of the transfer coefficient in accordance with temperature $h_{\mathrm{oil}}=f(T)$.

In order to validate the heat transfer coefficient, an axisymetric thermal model of the probe quenching was carried out using the finite element code Abaqus standard. The probe is meshed using the abaqus element type DCAX4. In this model, the heat transfer coefficient determined above (Fig. 8) was taken as a boundary condition. The obtained temperature was confronted in Figure 9 to the measured one.

The calculated curve (red curve), compared to the experimental one (blue curve), highlights a big similitude. This result allows thus tackling the numerical simulation of heat behavior during the leaf spring cambering and quenching.

\section{Finite element simulation}

Numerical simulation is based on the development of a thermo-mechanical model, from which we have presented in this article the thermal part with its experimental validation.

In this study, the heat source due to plastic deformation is neglected versus the convection and conduction heat

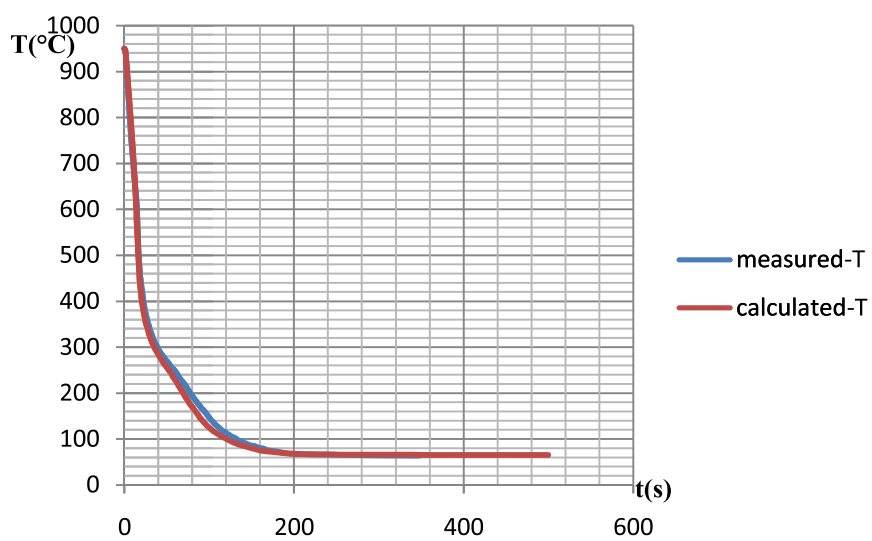

Fig. 9. Calculated and measured profile comparison of the temperature variation according to time.

flows. The effect of the phase transformation on thermal gradient is taken into account in the $h_{\text {oil }}$ coefficient.

The temperature distribution in the leaf is determined by the resolution of the transient heat equation (Eq. (2)) through the finite element simulation realized with the Abaqus calculation code in its implicit version:

$$
\rho(T) C(T) \frac{\partial T}{\partial t}-\operatorname{div}(\lambda(T) \underset{\operatorname{grad} T}{\longrightarrow})-q=0,
$$

with $T$ is the temperature, $t$ the time, $\rho$ the density, $C$ the specific heat, $\lambda$ the thermal conductivity, $\dot{q}$ the rate of heat generation term which is neglected in this work.

\subsection{Geometry}

The leaf spring presents two symmetry plans. Hence, study was limited to the quarter of the geometry in order to minimize the computation time.

The geometrical model relies on the three following components (Fig. 10):

- the rolled leaf: deformable 3D body;

- the two jaws of the press: isothermal rigid shell with temperature $T=25^{\circ} \mathrm{C}$;

- The upper and lower fingers of the press: isothermal rigid shell with temperature $T=25^{\circ} \mathrm{C}$.

The leaf is meshed using the abaqus element type C3D8T.

\subsection{Features of the steel EN-51CrV4(AISI-6150)}

The physical properties of $51 \mathrm{CrV} 4$ steel, such as the density, the thermal conductivity and the specific heat (Fig. 11) are introduced in the model according to temperature [17].

\subsection{Initial and boundary conditions}

The initial conditions considered in the FEM model are as below:

- the initial temperature of the leaf $T_{0}$ is supposed to be homogeneous. This temperature is fixed at $910{ }^{\circ} \mathrm{C}$ (average value of experimental measures); 


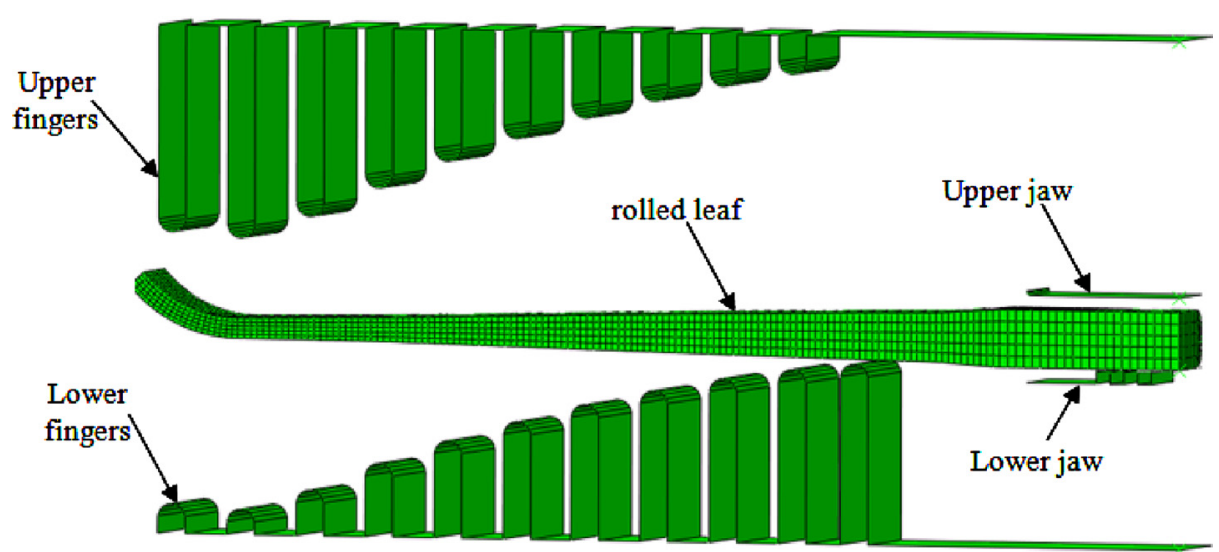

Fig. 10. Discretized geometrical model.
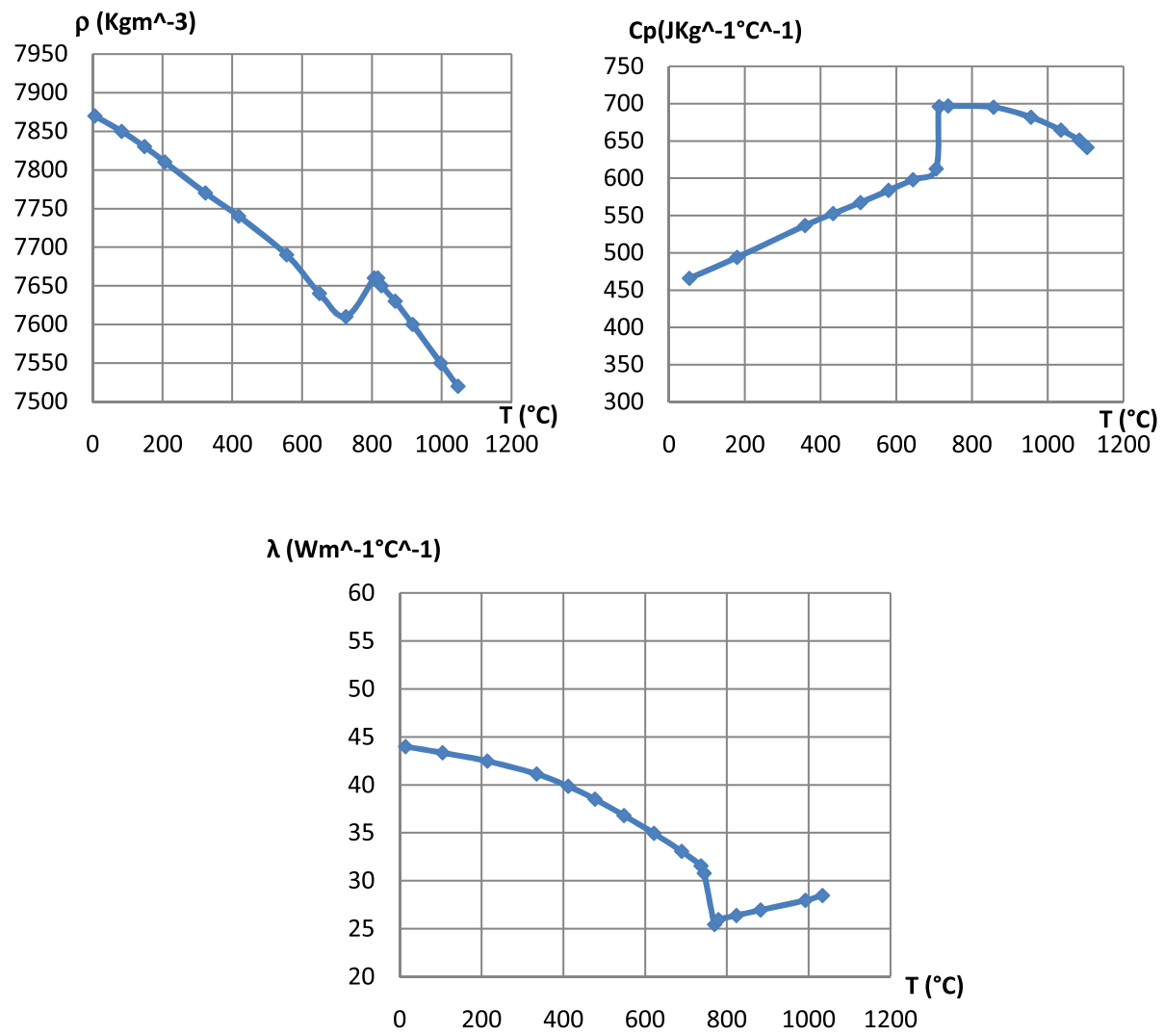

Fig. 11. Physical parameters of $51 \mathrm{CrV} 4$ steel.

- the temperature of the press is fixed at $25^{\circ} \mathrm{C}$;

- the temperature of the quenching oil is fixed at $73^{\circ} \mathrm{C}$ (experimental value).

The boundary conditions are as follows:

- radiation of the leaf towards the exterior environment: $\varepsilon$ $($ emissivity $)=0.85$ [18];

- convection between the exterior surface of the leaf $(\partial \Omega)$ and the exterior environment: $h_{\text {conv } / \text { air }}=7 \mathrm{~W} / \mathrm{m}^{2}{ }^{\circ} \mathrm{C}[19]$;

- conduction between the cambering press and the leaf: $h_{\mathrm{c}}=1200 \mathrm{~W} / \mathrm{m}^{2} \mathrm{~K}$ [20]. This coefficient depends on pressure [21]. The evolution of the heat transfer coefficient as a function of the contact pressure is determined by Merklein and Lechler [20]. In this study, $h_{\mathrm{c}}$ corresponds to a pressure of $40 \mathrm{bar}$;
- convection between the exterior surface of the leaf $(\partial \Omega)$ and the quenching oil: $h_{\mathrm{oil}}=f(T)$ (Fig. 8).

\section{Results and discussion}

The numerical results allow following the space-time evolution of the leaf temperature starting from its exit from the heat furnace to its exit from the quenching bath while going through the cambering operation. We present here this distribution at the end of each stage: after cambering and transfer towards the quenching bath at the time $t_{1}$ and after final cooling at the time $t_{2}$.

The leaf cambering and its transfer at the level of the quenching bath at the time $t_{1}$, creates a non uniform cooling. 


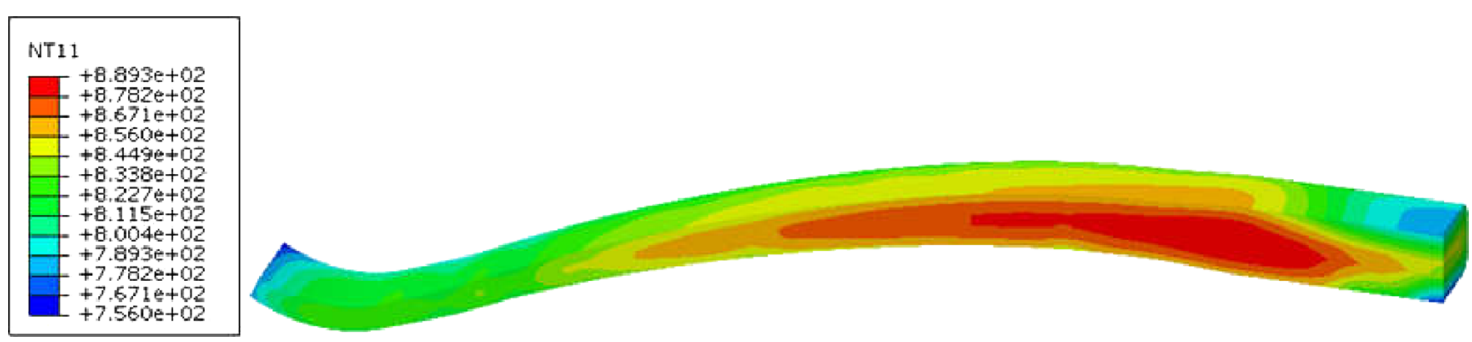

Fig. 12. Distribution of the leaf temperature before quenching $\left(t_{1}\right)$.

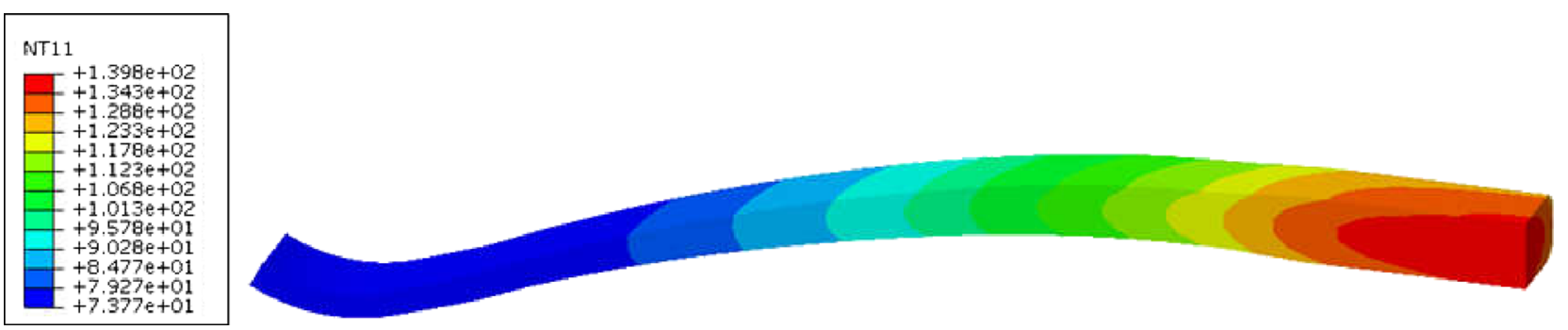

Fig. 13. Distribution of the leaf temperature at the exit from the quenching bath $\left(t_{2}\right)$.

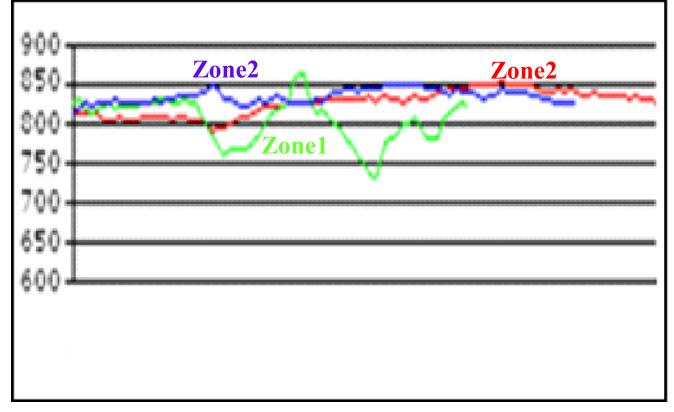

14.a: Measured temperature

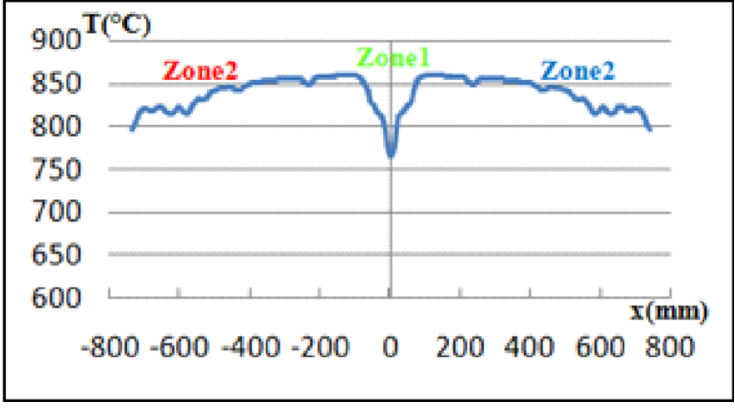

14.b: Calculated temperature

Fig. 14. Experimental and numerical temperature distribution of the leaf at $t_{1}$.

Indeed, the temperature at the leaf surface at the level of zone 2 varies between 800 and $850^{\circ} \mathrm{C}$. Whereas at the thick zone (zone 1) a thermal gradient is created between the surface and the core whose temperatures are around 760 and $850^{\circ} \mathrm{C}$, respectively (Fig. 12). The temperature decrease at the surface of this zone is associated to the contact between the press machine and the leaf during the cambering. The measured temperature, relative to the same cambering phase, reach $800^{\circ} \mathrm{C}$ at the extremities and varies between 860 and $730^{\circ} \mathrm{C}$ in the central zone.

The leaf after quenching and its exit from the oil bath at the time $t_{2}$, does not reach its entire cooling. Between the extremities to mid-length of zone 2, the temperature reaches that of the quenching bath, namely $73^{\circ} \mathrm{C}$ (Fig. 13). Whereas the central zone (zone 1) keeps a temperature superior to that of the bath, namely $140^{\circ} \mathrm{C}$. Between these two zones, the temperature varies. The measured temperature for this quenching phase are between 75 and $147^{\circ} \mathrm{C}$, respectively at the extremities and in the central zones.

Based on these results, the numerical values are equivalent to the experimental ones. In both cases, the profiles of the temperature distribution during cambering (Fig. 14) and also during quenching (Fig. 15) are almost the same.
The experimental temperature profile of zone 1 at $t_{1}$ (Fig. 14a) differs from that calculated (Fig. 14b) due to the presence of the robot clamps. Thus, the two techniques confirm that the quenching duration at about $440 \mathrm{~s}$ is insufficient to complete the cooling of the leaf because the central zone of the leaf chosen for this study did not reach the temperature of the quenching oil $\left(73^{\circ} \mathrm{C}\right)$ at its exit from the bath.

\section{Conclusion}

The numerical model aims to simulate the heat behavior of a leaf during its manufacturing throughout cambering and quenching phases. This model gives the space-time distribution of the temperature of the leaf from its austenitization to the exit of the oil bath.

Hence, this simulation highlights that at the end of the cambering and quenching operations, the temperatures at the extremities and central level are respectively of 73 and $140{ }^{\circ} \mathrm{C}$. These results are almost identical to those of the experimental measurements because the temperatures displayed in these zones are respectively 75 and $147^{\circ} \mathrm{C}$. Indeed, this numerical model could determine the space- 


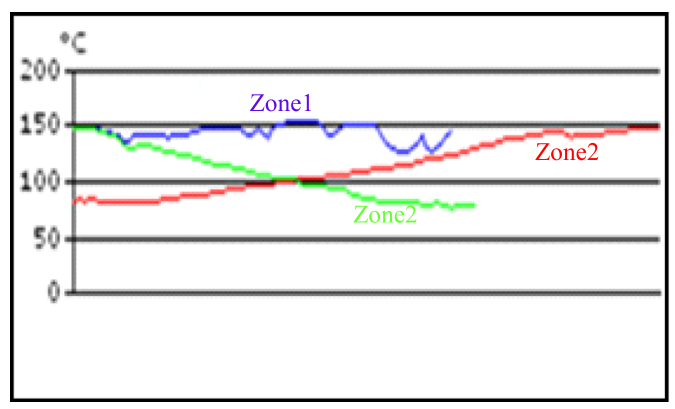

15.a: Measured temperature

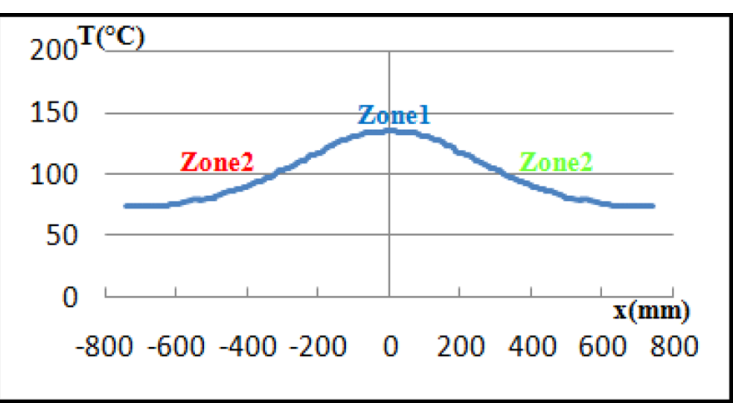

15.b: Calculated temperature

Fig. 15. Experimental and numerical temperature distribution of the leaf at $t_{2}$.

time distribution of temperature for any leaf geometry (shape and dimensions) during cambering and quenching operations. Thus it represents a reliable, fast and efficient tool to ensure optimal parameters for the faster development of new leaf ranges.

Acknowledgements. In memory of Prof. BOUBAKER Karem, the authors wish to thank him for his helpful comments and suggestions.

\section{References}

[1] H. Karbasian, A.E. Tekkaya, A review on hot stamping, J. Mater. Process. Technol. 210 (2010) 2103-2118

[2] F. Esiyork, G. Sevilgen, F. Kaya, Hot stamping applications in the automotive industry: coupled numerical simulation and FE-based die design, Int. J. Veh. Des. 71 (2016) 139-153

[3] M. Merklein, M. Wieland, M. Lechner, S. Bruschi, A. Ghiotti, Hot stamping of boron steel sheets with tailored properties: a review, J. Mater. Process. Technol. 228 (2016) 11-24

[4] T. Taylor, G. Fourlaris, P. Evans, G. Bright, New generation ultrahigh strength boron steel for automotive hot stamping technologies, Mater. Sci. Technol. 30 (2014) 818-826

[5] Norme Européenne EN-10089: Aciers laminés à chaudpour ressorts trempés et revenus-Conditions techniques de livraison (2002)

[6] C. Simsir, C. Gur, C. Hakan, A simulation of the quenching process for predicting temperature, microstructure and residual stresses, J. Mech. Eng. 56 (2010) 93-103

[7] S. Eck, P. Prevedel, S. Marsoner, Using finite element simulation to optimize the heat treatment of tire protection chains, J. Mater. Eng. Perform. 23 (2014) 1288-1295

[8] B. Taraba, S. Duehring, J. Spanielka, Effect of agitation work on heat transfer during cooling in oil isorapid $277 \mathrm{HM}, \mathrm{J}$. Mech. Eng. 58 (2012) 102-106

[9] T.S. Kumar, Influence of steel grade on surface cooling rates and heat flux during quenching, J. Mater. Eng. Perform. 22 (2013) 1848-1854

[10] H.S. Hasan, M.J. Pee, J.M. Jalil, Heat transfer coefficients during quenching of steels, Heat Mass Transf. 47 (2011) 315-321
[11] T.S. Kumar, Coupled analysis of surface heat flux, microstructure evolution, and hardness during immersion quenching of a medium carbon steel in plant conditions, Mater. Perform. Charact. 1 (2012) 1-22

[12] N. Chen, L. Han, W. Zhang, Enhancing mechanical properties and avoiding cracks by simulation of quenching connecting rods, Mater. Lett. 61 (2007) 3021-3024

[13] K. Funatani, M. Narazaki, M. Tanaka, Comparisons of probe design and cooling curve analysis methods, in: 19th ASM Heat Treating Society Conference and Exposition including Steel Heat Treating in the New Millenium, An International Symposium in Honor of Professor George Krauss, 1999, pp. $255-263$

[14] P. Auburtin, N. Morin, Thermo-mechanical modeling of the heat treatment for aluminum cylinder heads, Méc. Ind. 4 (2003) 319-325

[15] B. Liscic, T. Filetin, Measurement of quenching intensity, calculation of heat transfer coefficient and global database of liquid quenchants, Mater. Eng. 19 (2012) 52-63

[16] C.A. Rindby, A. Sahlin, Compilation and validation of heat transfer coefficients of quenching oils, Department of Materials and Manufacturing Technology, Master program advanced engineering materials, Chalmers University of technology, Gothenburg, Sweden, 2012, $25 \mathrm{p}$

[17] Collection ATS-OTUA (Office Technique pour l'Utulisation de l'acier), Proporiétés d'emploi des aciers, Dossier technique:acier 51CrV4, Fascicule de documentation A35-601: Aciers non alliés et alliés spéciaux pour traitement thermique, 1984, pp. 13-15

[18] F. Incropera, D. De Witt, Fundamentals of heat and mass transfer, $1985,59 \mathrm{p}$

[19] N. Malek, U. Vitoon, P. Ulrich, A numerical and experimental investigation into hot stamping of boron alloyed heat treated steels, Steel Res. Int. 79 (2008) 77-84

[20] M. Merklein, J. Lechler, T. Stoehr, Investigations on the thermal behavior of ultra high strength boron manganese steels within hot stamping, Int. J. Mater. Form. 2 (2009) 259-262

[21] Y. Chang, X. Tang, K. Zhao, Investigation of the factors influencing the interfacial heat transfer coefficient in hot stamping, J. Mater. Process. Technol. 228 (2016) 25-33

Cite this article as: S. Slama, M. Bouhafs, J. Bessrour, M.B. Jaber, H. Mokdadi, Numerical simulation of heat transfer during leaf spring industrial quenching process, Mechanics \& Industry 19, 304 (2018) 